\title{
A MULTIPHASE FLOW LOOP DESIGN FOR INVESTIGATING THE PARTIAL PHASE SEPARATION IN A PIPE TEE
}

\author{
Ahmed Saieed, Zeeshan Qadir Memon, Minh Cong Tran, \\ William PaO King SoON*
}

\author{
Universiti Teknologi PETRONAS, Department of Mechanical Engineering, 32610 Bandar Seri Iskandar, Perak, \\ Malaysia \\ * corresponding author: william.pao@utp.edu.my
}

\begin{abstract}
This article presents a design and commissioning of a multiphase flow loop, which was developed for scrutinizing the partial phase separation characteristics of pipe Tees. Its length is $9 \mathrm{~m}$ and its primary diameter is $0.078 \mathrm{~m}$ ( 3 inches). For the ease of modification, its design was kept modular, so that it could be used for testing various other pipe profiles. To validate this flow loop, the separation of a stratified-wavy flow was tested in a regular diameter ratio pipe Tee, and the gathered results were compared with previously published data. A good agreement was observed between the two data sources, which suggests that this flow loop is suitable for a further experimentation.
\end{abstract}

KEYwORDs: Flow loop design, T-junction, two-phase flow, flow patterns.

\section{INTRODUCTION}

Multiphase flow is a simultaneous flow of different phases. This type of flow can be witnessed in the pipelines of power plants, oil and gas industries, chemical plants, etc. As in these conditions, different phases flow together inside a shared space, so each phase has an effect on the overall flow. This makes the multiphase flow difficult to predict and handle. In addition, the shape of the interface between the operating phases makes it even more perplex [1, 2].

Conducting experiments for understanding the characteristics of a multiphase flow has always been a paramount analytical technique. In the past, numerous test flow loops have been developed either on industrial or academic scales. One such example of an industrial scale multiphase flow loop is Norsk Hydro Multi-Phase Flow Loop [3, shown in Figure 1. This flow loop was built in 1994 with an aim to probe a multiphase flow for studying the phase separation, foaming, dispersion, emulsions, transportation, and gas-water-oil flow characterization, etc. This experimental rig has a pipe diameter of $0.076 \mathrm{~m}$ and is $200 \mathrm{~m}$ long. The fluids that can be tested in this flow loop are water, hydrocarbon gases and oils. This rig was designed to handle a maximum operating pressure and a temperature of about 110 bar and $140{ }^{\circ} \mathrm{C}$, respectively. The flow cycle starts from a three-phase separation tank, which was used to separate and store all three phases. From this tank, all three phases were individually pumped into the flow loop. These phases were then combined with the help of either a Tjunction or Y-junction, depending upon the required flow pattern. For generating a stratified flow regime, the Y-junction was utilized, while the T-junction was employed for generating a dispersed flow. After the flow development, this three-phase flow was intro- duced into the test section which led it back to the separator. In addition to the three-phase separator, two single-phase buffer tanks were also provided to store the water and oil. A liquid heat exchanger was installed for controlling the temperature of the water and oil, which consequently controls the temperature of the three-phase stream.

Institut Français Du Pétrole (IFP) 4] is another pioneer multiphase flow testing facility. In Figure2, a small flow loop of this test facility is highlighted. The pipe diameter and total length of this flow loop are $0.025 \mathrm{~m}$ and $50 \mathrm{~m}$, respectively. The maximum static pressure envelope of this rig is $5000 \mathrm{kPa}$ and the maximum flow rates of gas and liquid phases that can be studied are 0.037 and $0.098 \mathrm{~m}^{3} / \mathrm{s}$, respectively. The IFP flow facility is compatible with operating fluids, such as water, fuel oil, and methane or nitrogen. A two-phase pump coupled with a controllable speed motor was used to pump the gas-liquid flow into the flow loop. After the pump, two multiphase separators were provided. At the liquid outlets of the second multiphase separator (horizontal separator), three boasting pumps were installed to further increase the flow rates of the liquid phases, if required. In the oil flowline, a water-cooled heat exchanger was used to regulate the temperature of the oil. In order to provide a smooth feed to the concerned equipment, a buffer tank was used, which is capable of absorbing the fluctuations in gas to liquid ratios.

Figure 3 is depicting the layout of the National Engineering Laboratory (NEL), UK multiphase flow loop [4]. In comparison to the IFP, this test facility uses a different approach for pumping fluids into the system. Instead of a one main multiphase pump, NEL employed separate single-phase pumps for water and oil, whereas nitrogen gas was taken from a liquid nitrogen tank. Before the mixing, phase flow rates were 


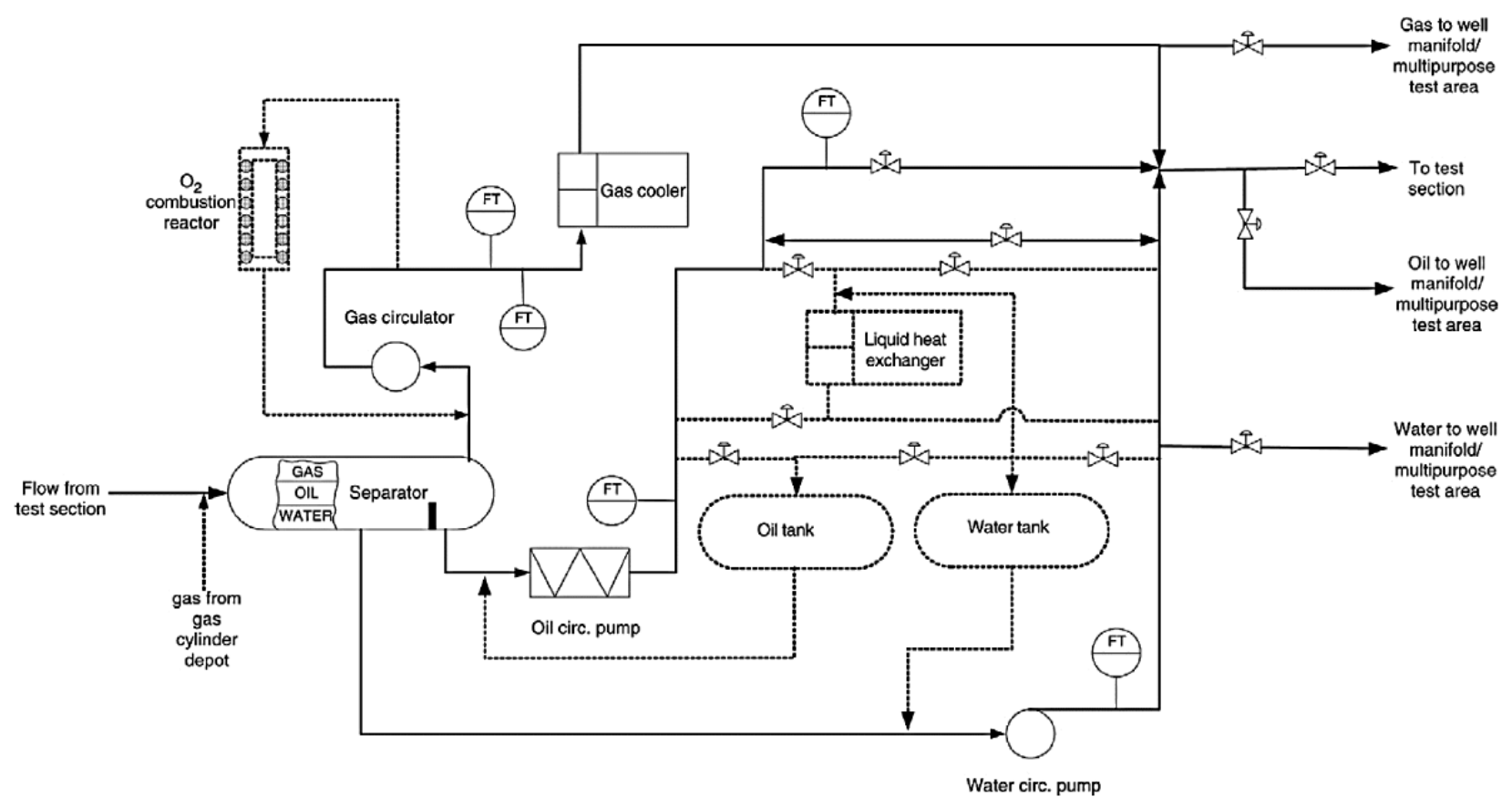

Figure 1. Layout of Norsk Hydro Multiphase Flow Loop [3].

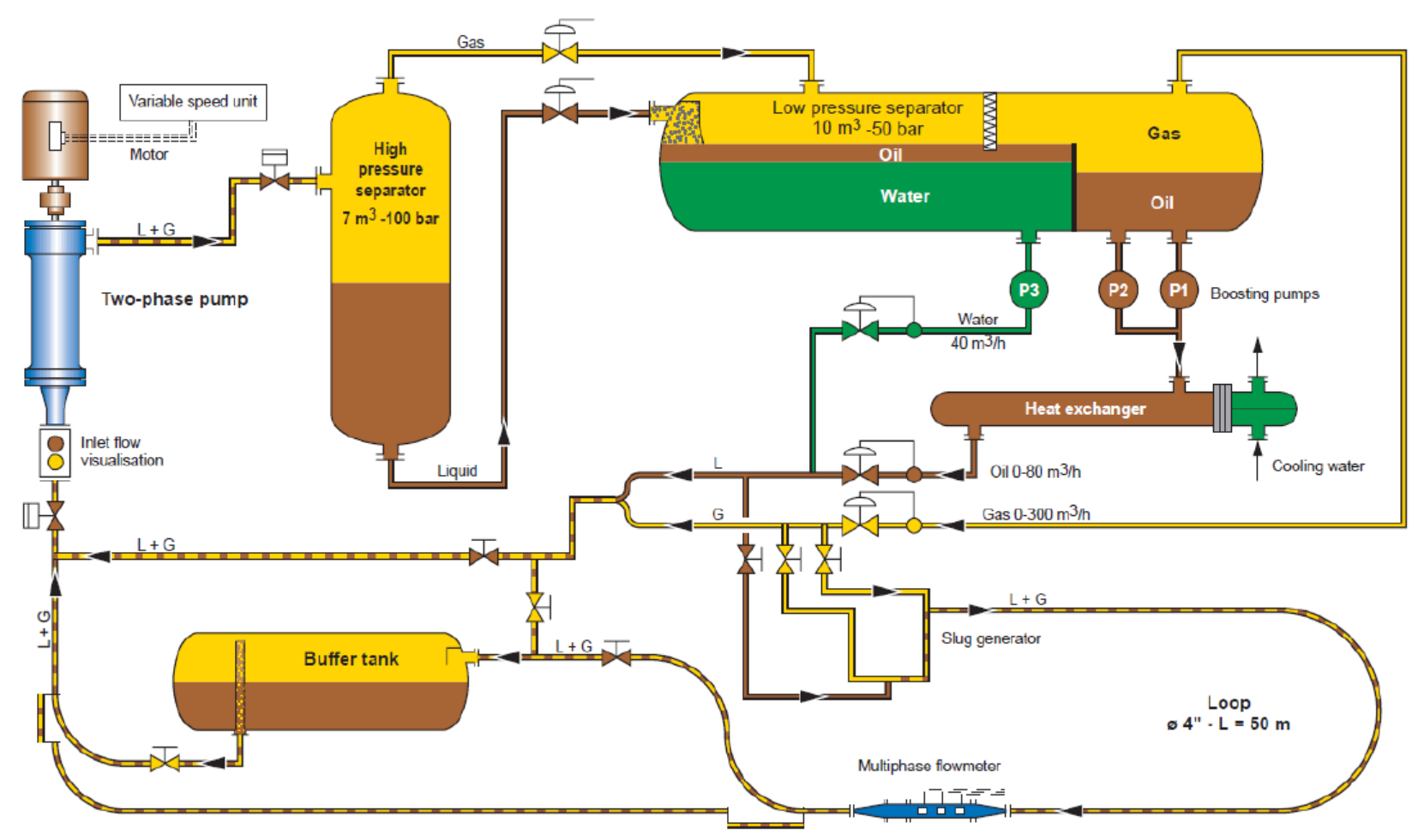

Figure 2. IFP multiphase flow loop design 44. 


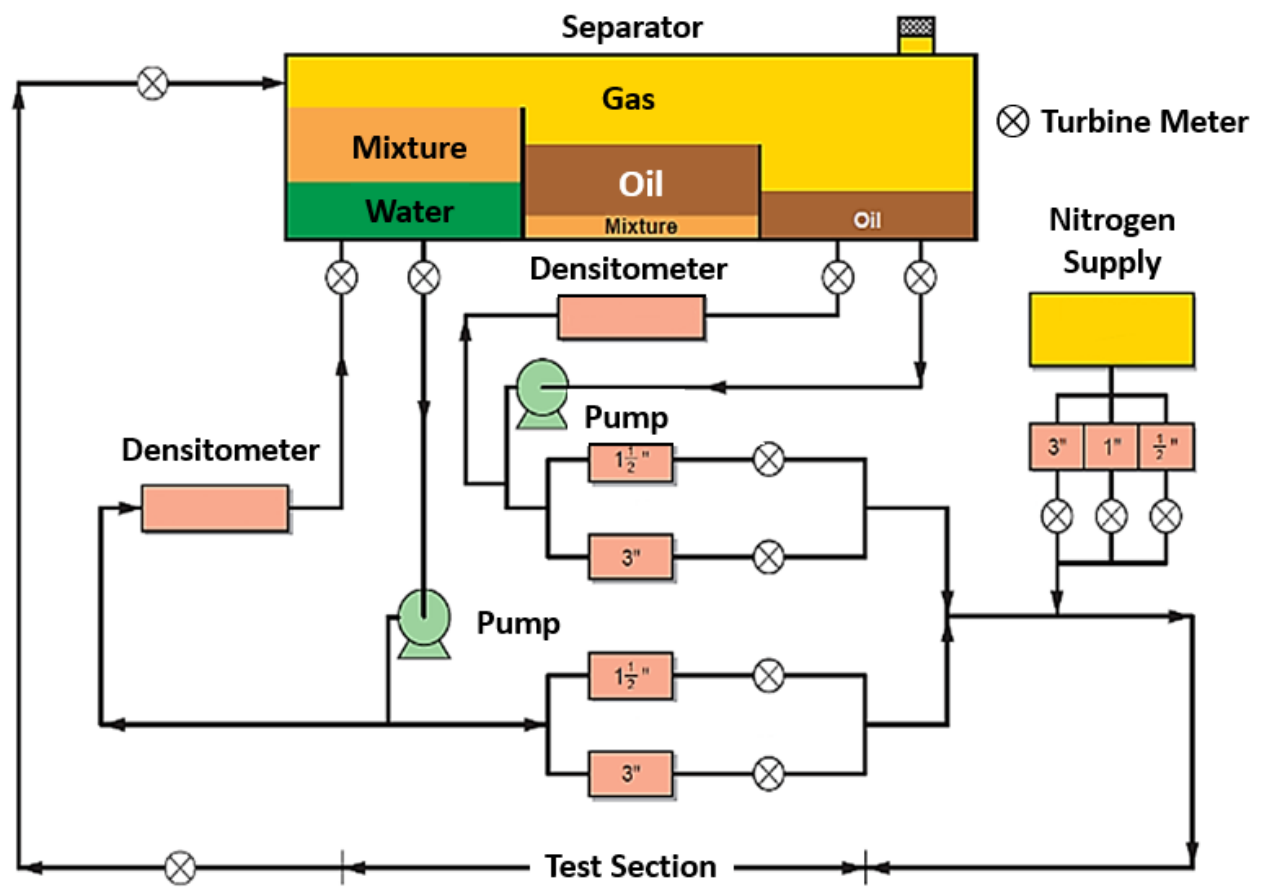

FIgURE 3. NEL multiphase flow loop design [4.

rectified and measured. The excess water and oil were sent back to the separator tank using a return flowline. This flowline was equipped with a densitometer for monitoring the density of the liquid phases. After mixing, the three-phase flow was passed through a $40 \mathrm{~m}$ long test section. Towards the end of this section, the flow rate of the exiting fluid stream was measured with the help of a venturi meter. This fluid stream then enters a three-phase separator, where the nitrogen gas was exhausted to the atmosphere, and both liquid phases were separated and stored.

The abovementioned three flow loops were general purpose flow loops, housed by facilities, which were built for testing the multiphase flow at an industrial scale. There are certain differences in these flow loops, such as the methods used for pumping fluids, pipe diameter, and operating phases. However, the general design philosophy is the same. In order to design a specialized flow loop for testing the multiphase separation in a T-junction, few more flow loops are mentioned, which were specially built or modified for this purpose. Figure 4 presents a two-phase flow loop used by Wren [5] for testing the phase separation in a different configuration of T-junctions, under various flow conditions. The main pipeline diameter of this flow loop is $0.127 \mathrm{~m}$, and it is capable of testing single or two combined T-junctions, different orientations of side arm and T-junction inserts. Wren [5] used two Tjunctions with a diameter ratio 1 and 0.6 for his study. It can be seen in Figure 4 that, for increasing the flow measuring range, a set of three rotameters and a turbine meter were used at the water inlet flowline. Each rotameter had a different flow measuring range, thus as a whole, they could cover a wide spectrum of flow rates. For very high-water flow rates, a turbine meter was used. Air was introduced into the system with the help of a blower, and it was regulated by using an air bleed and orifice plate. The maximum air and water flow rates mentioned in this study were 0.304 and $0.0071 \mathrm{~m}^{3} / \mathrm{s}$, respectively. Air and water were mixed with the help of a pipe mixer. A length of $4 \mathrm{~m}$ was provided after the mixer for ensuring the proper development of a flow regime. This length is called the flow development length. The obtained two-phase stream was then introduced into the T-junction, which was made by drilling holes in a $0.2 \times 0.2 \mathrm{~m}^{2}$ acrylic resin block. Butterfly valves were provided after each outlet of the T-junction to replicate the pressure generated by the equipment installed after the $\mathrm{T}$-junction in industrial conditions. The air-water streams emerging from both outlets of the T-junction were discharged into their respective cyclones. At this point, the air was released into the atmosphere after measuring its flow rate with the help of an orifice or a venturi meter, whereas the water was collected in a tank placed on a load cell to measure its weight overtime for finding its volumetric flow rate. This study was used as a benchmark to validate the present air-water flow loop.

Another flow loop designed for testing the phase of distribution in a $\mathrm{T}$-junction was reported by Das et al. [6], shown in Figure 5. The pipeline diameter of this two-phase flow loop was $0.005 \mathrm{~m}$. It can be seen in Figure 5 that the overall layout of this flow loop is similar to that of Wren's [5] test setup. In this experimental rig as well, the flow rates of air and water were regulated and measured with the help of valves and rotameters. After combining the air and water in the mixer, the two-phase flow was channeled into a $1.76 \mathrm{~m}$ long pipe for the flow development. This pipe led the flow into the T-junction where the flow 


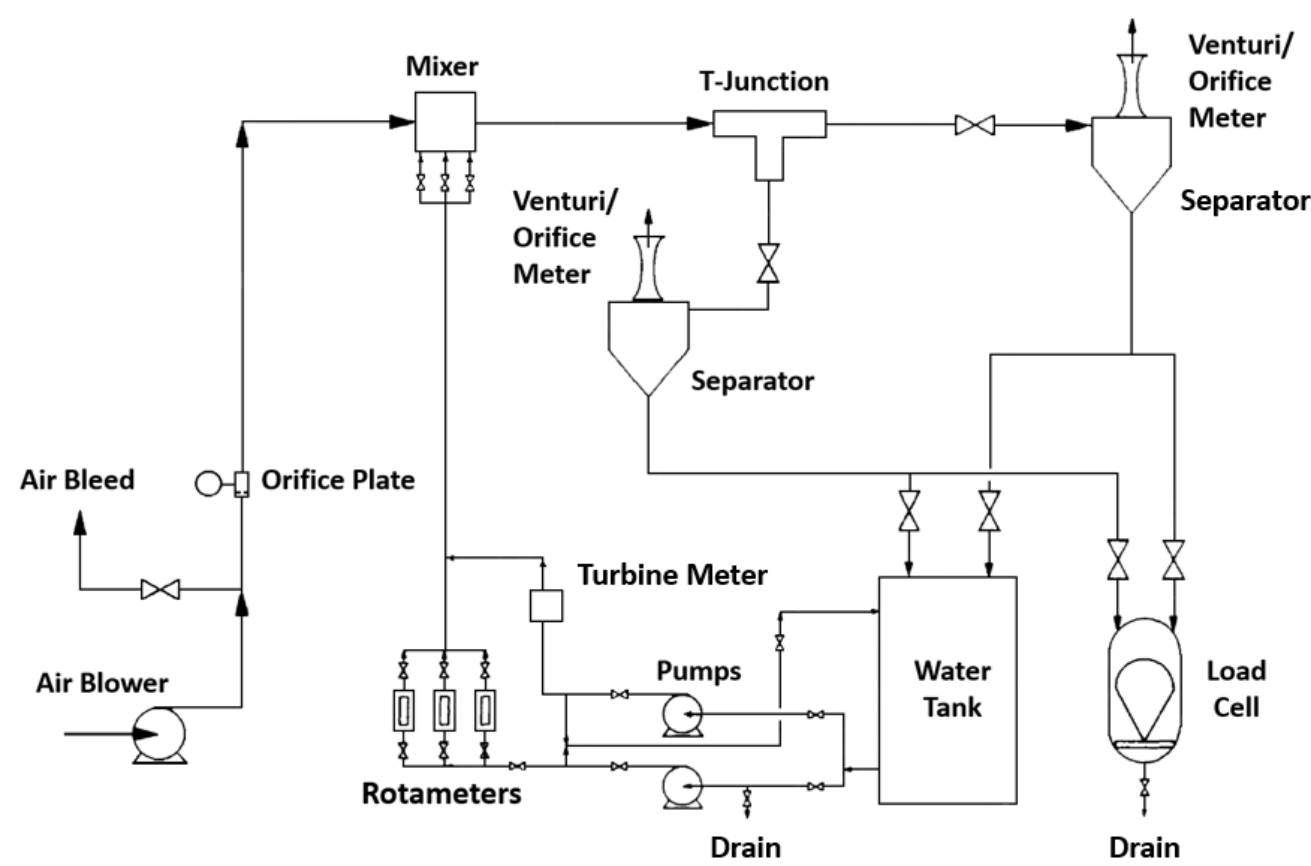

Figure 4. Two-phase flow loop layout by Wren [5].

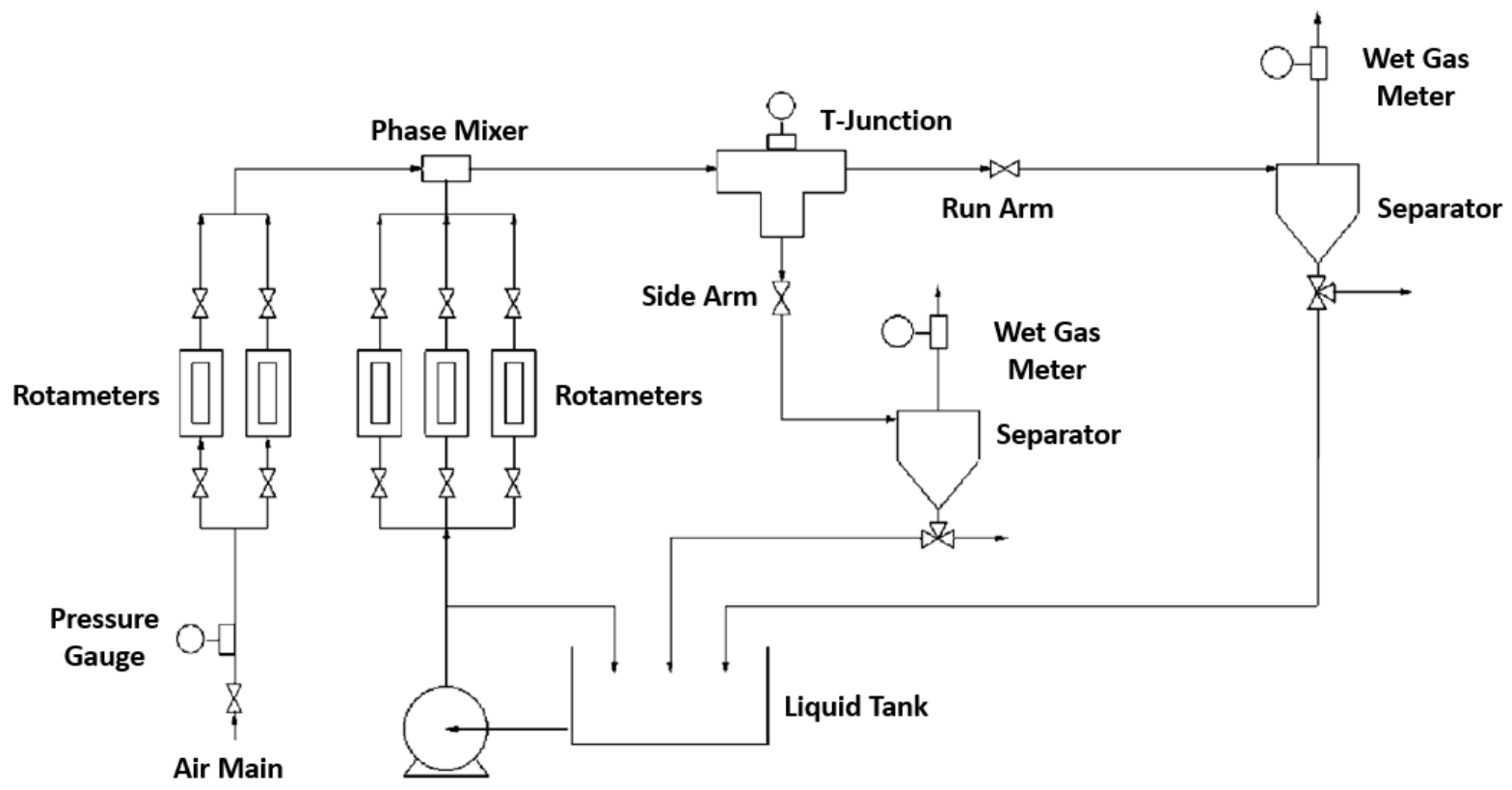

Figure 5. Two-phase flow loop used by Das et al. [6]. 
was distributed among the two outlets. They also made their T-junction by machining $0.005 \mathrm{~m}$ diameter holes in an acrylic resin block. Next, these two fluid streams were passed through two valves. Towards the end of this flow cycle, both streams entered their corresponding cyclones, where the flow rates of air and water were measured using the method reported by Wren [5]. After taking the measurements, the water was sent back to the main supply tank, and the air was released into the atmosphere. Das et al. 6] reported a maximum pressure and flow rates of the air and water of $191 \mathrm{kPa}, 9.8 \times 10^{-5}$ and $1.9 \times 10^{-7} \mathrm{~m}^{3} / \mathrm{s}$, respectively.

A review of different multiphase flow loops suggests that, irrespective of the scale, the general components of a multiphase flow loop are:

- Phase supply

- Phase moving devices (pumps and compressors)

- Flow measuring devices (rotameters and turbine meters etc.)

- Flow controlling devices (valves)

- Phase mixer

- Test specimen

- Phase separators

The specifications of these devices are decided according to the demands. Based on the stated design philosophy, this paper presents an air-water two-phase flow loop to study the partial phase separation in a T-junction, as a multiphase flow loop design guideline.

\section{Current Air-Water flow loop}

Figure 6 is depicting a 2D schematic of the present air-water flow loop design, while Table 1 enlists its operating envelope. In Figure 6, the test section and flow development lengths that are $6 \mathrm{~m}$ and $8 \mathrm{~m}$, respectively, can be seen. It should be noted that the total horizontal length of this flow loop is $9 \mathrm{~m}$ as shown in Figure 6 Due to the 2D nature of this schematic diagram, the turning of the pipes to the back of the test section in the z-direction cannot be portrayed. Hence, to clarify, the pipeline starts from the airflow control valve and then goes straight up to the gate valve fitted after the horizontal outlet of the T-junction. After this gate valve, the pipe turns towards the liquid holdup tank, which is located at the back of the test section. Figure 7 presents the photograph of the $6 \mathrm{~m}$ flow development length, which was constructed by bolting three $2-\mathrm{m}$ pipe sections. The operating temperature of the air-water flow loop is $25^{\circ} \mathrm{C}$.

This flow loop was designed to test the two-phase separation inside a T-junction by first developing the desired flow regime, and then passing it through the T-junction. The major components of this setup are discussed under the following headings:

\section{Materials}

The flowline of the presented flow loop was made from PVC and Perspex pipes. Perspex pipes were used for the pipe section between the mixer and two outlets of the T-junction. The main purpose behind keeping this section transparent was to observe and ensure the development of the flow regime, as well as to visually analyse the phase separation process. Likewise, plastic tanks were used for separating, holding and supplying water to the flow loop.

For controlling the flow, brass valves were used in order to prevent rusting. This is because rust would change the composition of the working fluids, which would ultimately affect the readings of the flow measuring devices.

\section{AIR COMPRESSOR}

For feeding this flow loop with air, a $5 \mathrm{hp}$ two-stage compressor was employed, as illustrated in Figure 6 It has a maximum free air delivery of $0.00908 \mathrm{~m}^{3} / \mathrm{s}$ $(545 \mathrm{l} / \mathrm{min})$ at an 8 bar pressure. A flexible hose was used to connect the compressor with the flow loop.

\section{Centrifugal Pump}

For introducing water into the flowline, a centrifugal pump was installed, as shown in Figure 6 This pump is capable of delivering water at a maximum flow rate of $0.0167 \mathrm{~m}^{3} / \mathrm{s}$, with 8 to $10 \mathrm{~m}$ of pressure head. It is driven by a 3 hp motor which has a maximum speed of 1450 RPM.

\section{WATER INLET FLOWMETER}

Figure 6 depicts the rotameter that was used to measure the volumetric flow rate of the water at its inlet. This flowmeter has a connection size of $0.078 \mathrm{~m}$, and its measuring range is between $0.00133-0.0133 \mathrm{~m}^{3} / \mathrm{sec}$ ( 80 to $800 \mathrm{l} / \mathrm{min}$ ). Just before this flowmeter, a gate valve was installed to control the flow rate of the water at the inlet.

\section{Pressure SEnsors}

Three pressure sensors were used in the air-water flow loop to inspect the pressure profile across the T-junction. These pressure sensors have a measuring range of 0 to 20 bars, with an accuracy of $1 \%$ at a room temperature.

\section{SEPARATION TANK}

The separation tank shown in Figure 6 served two purposes. Firstly, it separates the two phases coming from the side arm of the T-junction by releasing air into the atmosphere and collecting water. Secondly, it measures the amount of air and water extracted into the side arm, at any given operating condition.

It is a custom made 44-gallon tank, build on the design described by Baker [7] with slight modifications. This design is presented in Figure 8 It can be seen in Figure 8 that the air-water flow coming from the side arm enters the separation tank through a flow distribution system. This flow distribution system 


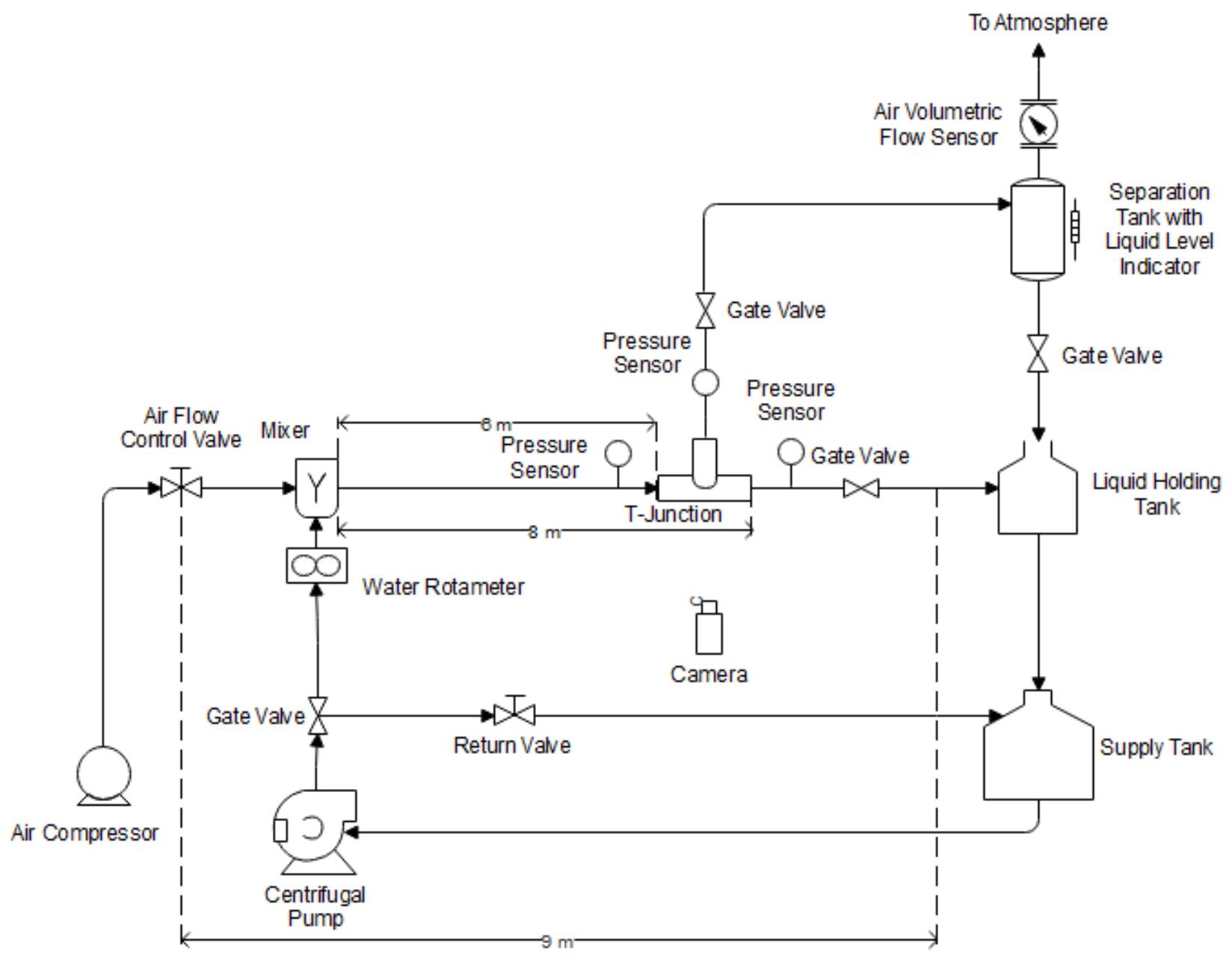

Figure 6. Air-water flow loop design.

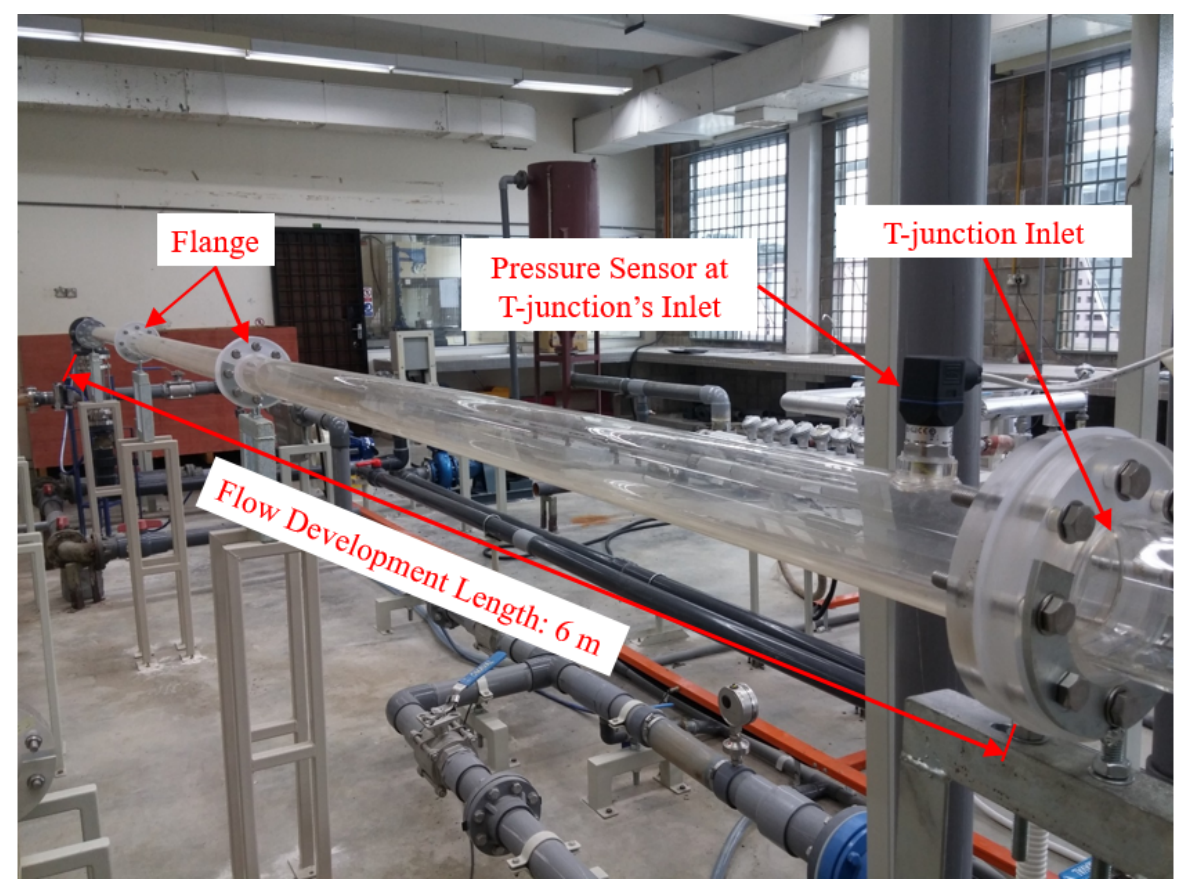

Figure 7. Construction of $6 \mathrm{~m}$ (77D) flow regime development pipe by connecting three 2-m Perspex pipes with the help of flanges. 


\begin{tabular}{|c|c|c|}
\hline Parameter & Specification & Instrument details \\
\hline Flowline pipe diameter & $0.078 \mathrm{~m}$ (3 inches) & \multirow{5}{*}{$\begin{array}{l}\text { Pipe Material: } \\
\text { PVC + Perspex }\end{array}$} \\
\hline Length of the flow Loop & $9 \mathrm{~m}$ & \\
\hline Flow Development Length & $6 \mathrm{~m}$ & \\
\hline T-junction length & $2 \mathrm{~m}$ & \\
\hline T-junction height & $1 \mathrm{~m}$ & \\
\hline Maximum air delivery of compressor & $0.00908 \mathrm{~m}^{3} / \mathrm{s}$ & Manufacturer: SWAN \\
\hline Maximum pressure of compressor & 8 bar & Model: SPV-205 \\
\hline Maximum flow rate of centrifugal pump & $0.0167 \mathrm{~m}^{3} / \mathrm{s}$ & Manufacturer: TECO \\
\hline Pressure head of centrifugal pump & $8-10 m$ & Model: Regaline $65-16$ \\
\hline \multirow{3}{*}{ Measuring range of air flow sensor } & \multirow{3}{*}{$\begin{array}{l}\text { Overall range: } 0 \text { to } 0.954 \mathrm{~m}^{3} / \mathrm{s} \\
\text { Calibrated range: } 0 \text { to } 0.01 \mathrm{~m}^{3} / \mathrm{s}\end{array}$} & Manufacturer: ifm \\
\hline & & Model: SA5000 \\
\hline & & Accuracy: $5 \%$ \\
\hline \multirow{3}{*}{ Measuring range of water rotameter } & \multirow{3}{*}{0.0013 to $0.013 \mathrm{~m}^{3} / \mathrm{s}$} & Manufacturer: New Flow \\
\hline & & Model: BF-3017 \\
\hline & & Accuracy: $2.5 \%$ \\
\hline \multirow{3}{*}{ Pressure measuring range } & \multirow{3}{*}{$0-20$ bar } & Manufacturer: MIKA \\
\hline & & Model: A-10 \\
\hline & & Accuracy: $1 \%$ \\
\hline \multirow{3}{*}{ Sampling rate of data logger } & \multirow{3}{*}{$10 \mathrm{~ms}-1$ hour } & \\
\hline & & Model: midi Logger GL240 \\
\hline & & Number of Channels: 10 \\
\hline
\end{tabular}

TABLE 1. Specifications of the air-water flow loop.

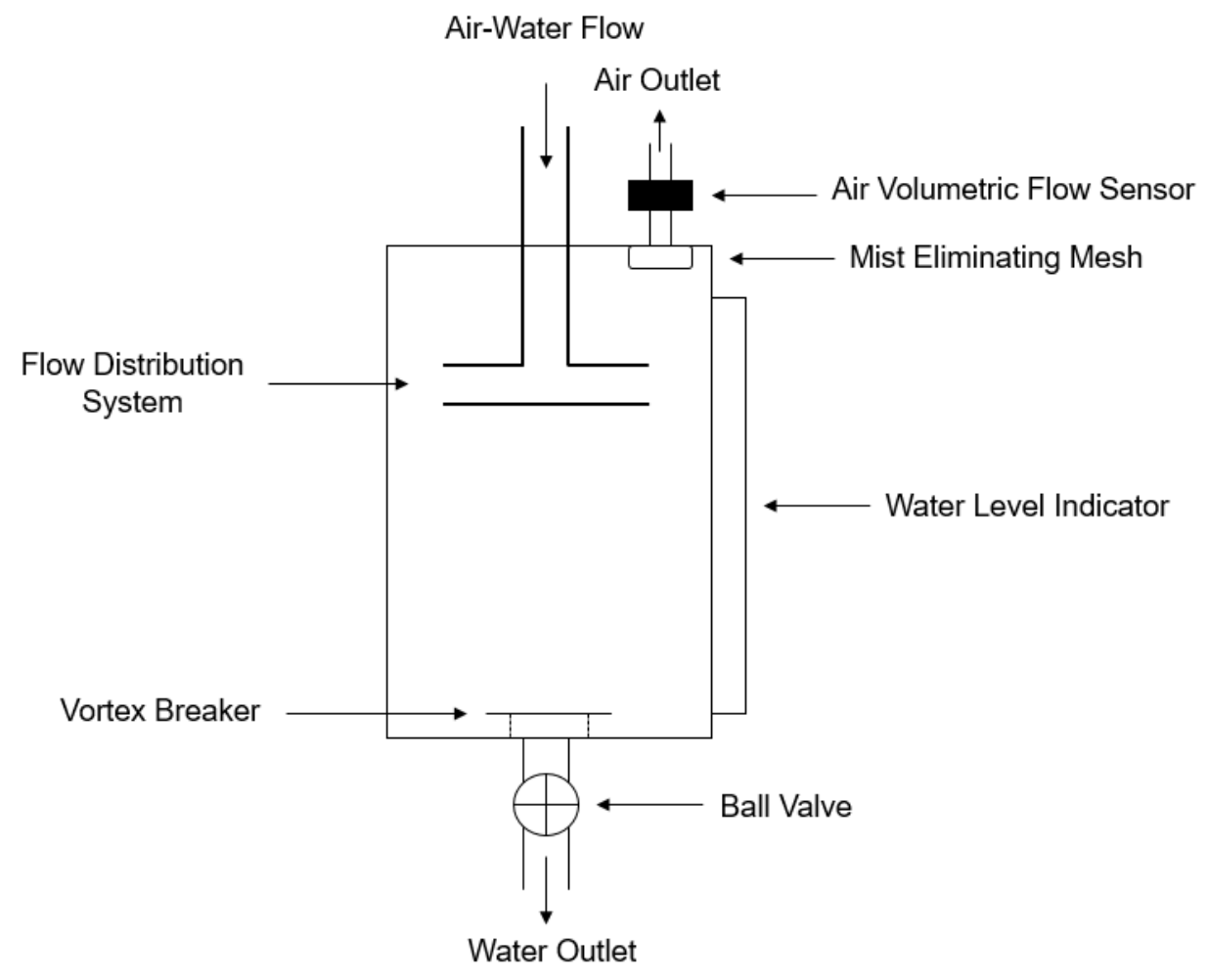

Figure 8. Design of the air-water separation tank. 
was used to avoid splashing and jetting of the fluid stream. Once in the separation tank, the air rises towards the air outlet where it passes through a mist eliminating mesh, which captures the water droplets in the air. This air then passes through the air volumetric flow sensor before exiting into the atmosphere. For measuring the amount of water exiting through the side arm, the separation tank was equipped with a water level indicator and a ball valve, which was installed at the water outlet of the separation tank. By closing this valve, water accumulates in the separation tank. The rise in the water level was then noted over time, before reopening the ball valve. This gave the volumetric flow rate of the water exiting through the side arm of the T-junction.

\section{AIR VOLUMETRIC FLOW SENSOR}

The air volumetric flow sensor fitted at the air outlet of the separation, shown in Figure 6 and Figure 8. performed two tasks in the air-water separation tank. Firstly, it was used to measure the volumetric flow rate of air that was separated from the water in the separation tank. Secondly, this flow sensor was also used to measure the inlet volumetric flow of the air. For this purpose, the valves in the water inlet flowline, after the run arm and at the water outlet of the separation tank, were fully closed. Therefore, the air entering into the flow loop had only one way to go and that was towards this flow sensor. A similar approach was also used by Azzopardi and Rea 8] for measuring the inlet flow rates of the phases coming from an oil well.

Although the flow rate measuring range of this flow sensor is 0 to $0.954 \mathrm{~m}^{3} / \mathrm{s}$, this flow sensor can be calibrated. Thus, it was calibrated to an operating range of 0 to $0.01 \mathrm{~m}^{3} / \mathrm{s}$ in order to match the maximum flow rate of the air compressor $\left(0.00908 \mathrm{~m}^{3} / \mathrm{s}\right)$.

\section{LIQUID HOLDUP AND SUPPLY TANKS}

For supplying this loop with a tap water, a 100 gallon supply tank was employed. It is an open top water tank which is fitted with a float valve for maintaining the water level. Moreover, a 44-gallon liquid holdup tank was utilized to collect the water coming from the separation tank and the run arm of the T-junction. The main objective of this tank is to provide extra space and time to the air and water for proper separation before the water is reinjected into the flowline. This step is important to prevent the cavitation of the centrifugal pump.

\section{DATA ACQUISITION SYSTEM}

A 10-channel data logger was used to record the measurements from the three pressure sensors and the air volumetric flow sensor. It is a commercial data logger using a custom software. This data logger was connected to a computer through a USB connector for analysing the recorded measurements.

\section{Customizable Design}

The flowline between the mixer and the T-junction was built by joining 2-m pipe sections which were connected with the help of flanges. This was done to make this flow loop easily modifiable so new pipe profiles can be installed at any place between the mixer and the outlets. As flanges were used to connect different pipe sections, various diameter pipe sections can be tested in this flow loop. Furthermore, the test T-junction can be easily replaced with any other pipe profile. Hence, this flow loop can also be used to study a series combination of T-junctions as well as for analyzing the flow characteristics in a straight horizontal pipe with very little modifications.

\section{VALIDATION}

To validate the air-water flow loop, experiments were performed by reproducing the results reported by Wren [5] for a regular T-junction. He studied the extraction of air (FA) and water (FW) under stratified and annular flow conditions in different pipe T-junction profiles. The expressions for evaluating FA and FW are written as:

$$
\begin{gathered}
F_{A}=\frac{\dot{V}_{A L}}{\dot{V}_{A I}} \\
F_{W}=\frac{\dot{V}_{W L}}{\dot{V}_{W I}}
\end{gathered}
$$

Here, $\dot{V}$ is the phase volumetric flow rate and the subscripts $A, W, I$ and $L$ represents air, water, inlet and lateral outlet of the T-junction.

The air and water superficial velocities, which Wren [5] used in his study, were greater in comparison to the operating capacity of the air-water flow loop. As a rectification measure, the air to water velocity ratios of the present tests and Wren [5] experiments were kept identical [9, 10. Moreover, it was ensured that the flow regime developed from the chosen air, and water superficial velocities were a stratified-wavy flow, as reported by Wren [5]. It should be observed here that the sampling rate of a one measurement per second was used for this benchmark analysis. The velocity ratio (VR) can be mathematically illustrated as:

$$
\mathrm{VR}=\frac{v_{S A}}{v_{S W}}
$$

Where $v_{S A}$ and $v_{S W}$ stand for the air and water superficial velocity at the inlet.

Figures 9 to 13 illustrate the comparison between the obtained results and the benchmark cases. The average disagreements witnessed in these cases varied between $2.5 \%$ to $4.84 \%$. Similarly, it can also be observed that, in this analysis, a slightly higher liquid extraction was obtained as compared to Wren's [5] results. This can be explained by considering the difference in pipe diameters of the two setups. According to Stacey et al. [11, small diameter T-junctions deliver a higher liquid carryover in contrast to large 


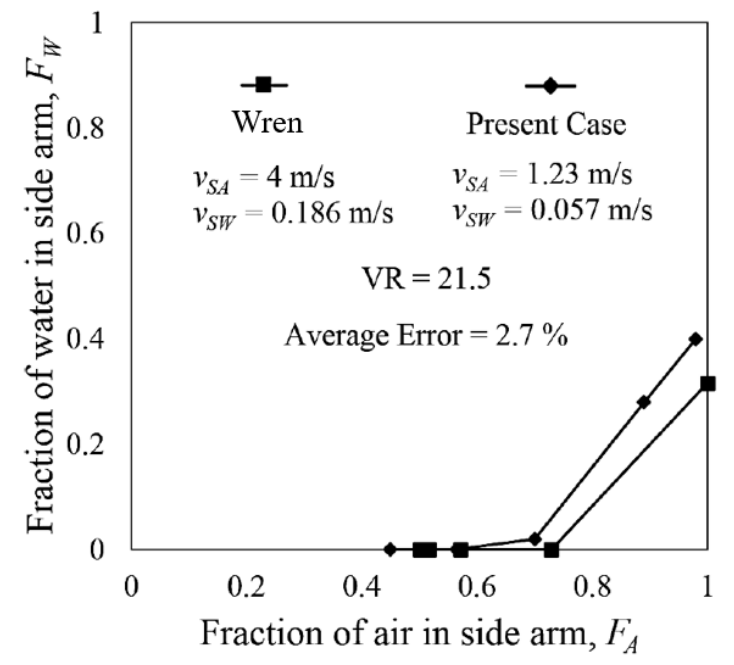

Figure 9. The comparison between Wren's [5] study and presented results: benchmark case 1 .

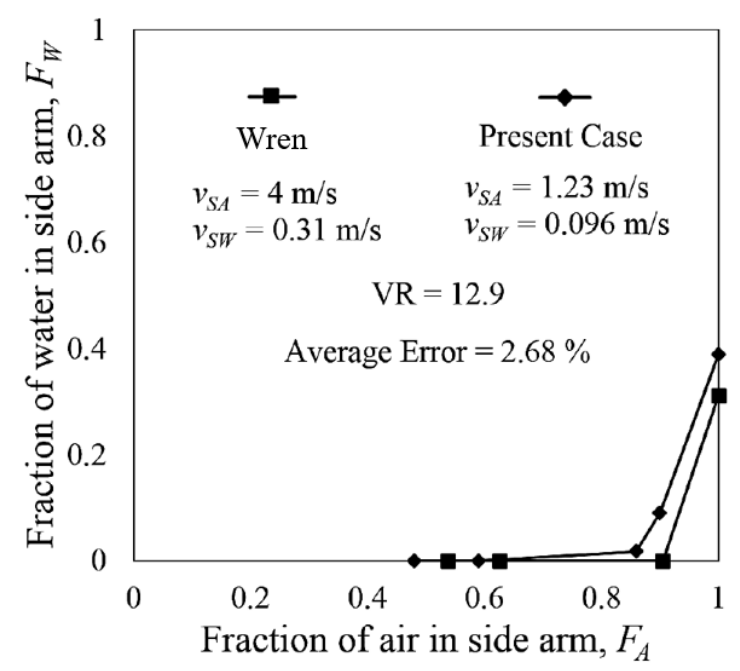

Figure 10. The comparison between Wren's 5 study and presented results: benchmark case 2 .

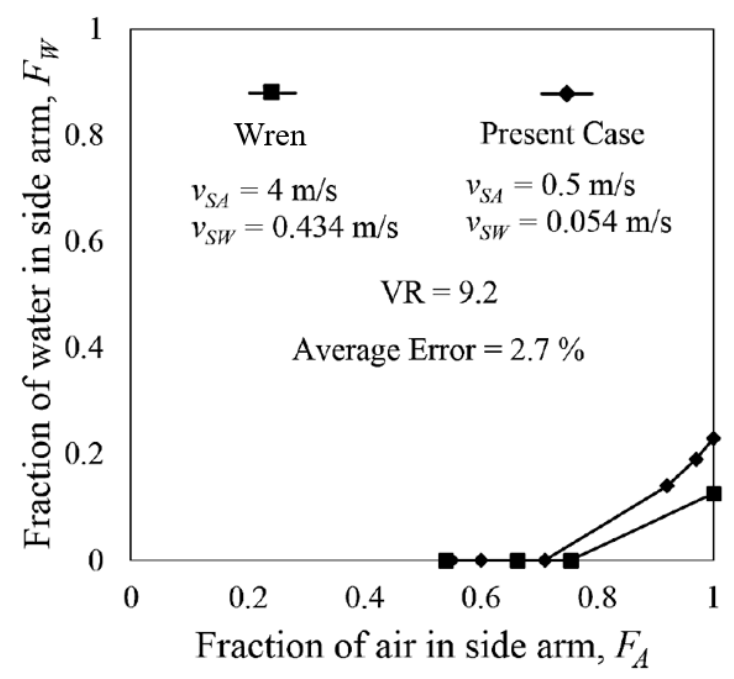

Figure 11. The comparison between Wren's [5] study and presented results: benchmark case 3 .

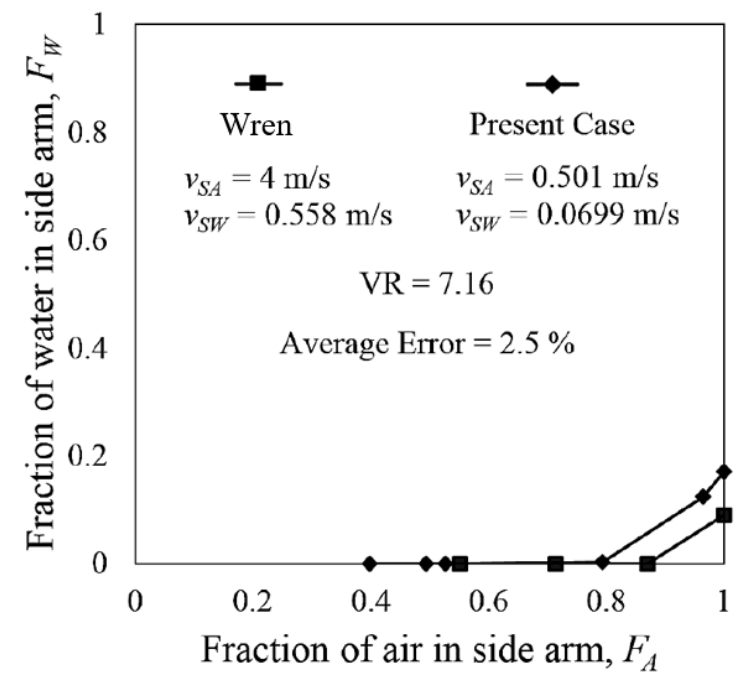

FiguRE 12. The comparison between Wren's 5 study and presented results: benchmark case 4 .

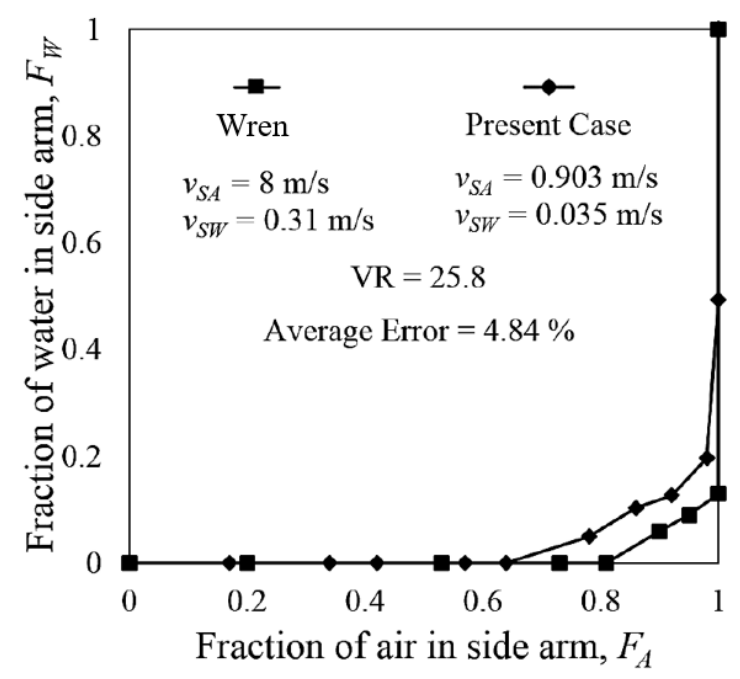

Figure 13. The comparison between Wren's [5] study and presented results: benchmark case 5 .

diameter T-junctions. Because the pipe diameter of Wren's [5] test loop was $0.127 \mathrm{~m}$ and the pipe diameter of the air-water flow loop was $0.078 \mathrm{~m}$, the difference in the liquid takeoff is justified. Moreover, taking into account that this experimental setup was custom built, the errors witnessed in the validation study are fairly small, and thus the air-water flow loop is fit for further studies. This rig was used to extensively analyse the partial phase separation in pipe T-junctions, and the obtained results were reported by Saieed et al. 12 14.

Figures 14 to 18 illustrate the condition of the flow during each benchmark case. It can be noticed that, at higher air and water superficial velocities, the interface between the operating phases was significantly violent. Likewise, the level of water in the run arm was observed to be higher as compared to the main arm. This is due to the partial extraction of the air in the side arm, which results in more water flowing into the run arm with a small percentage of air. 


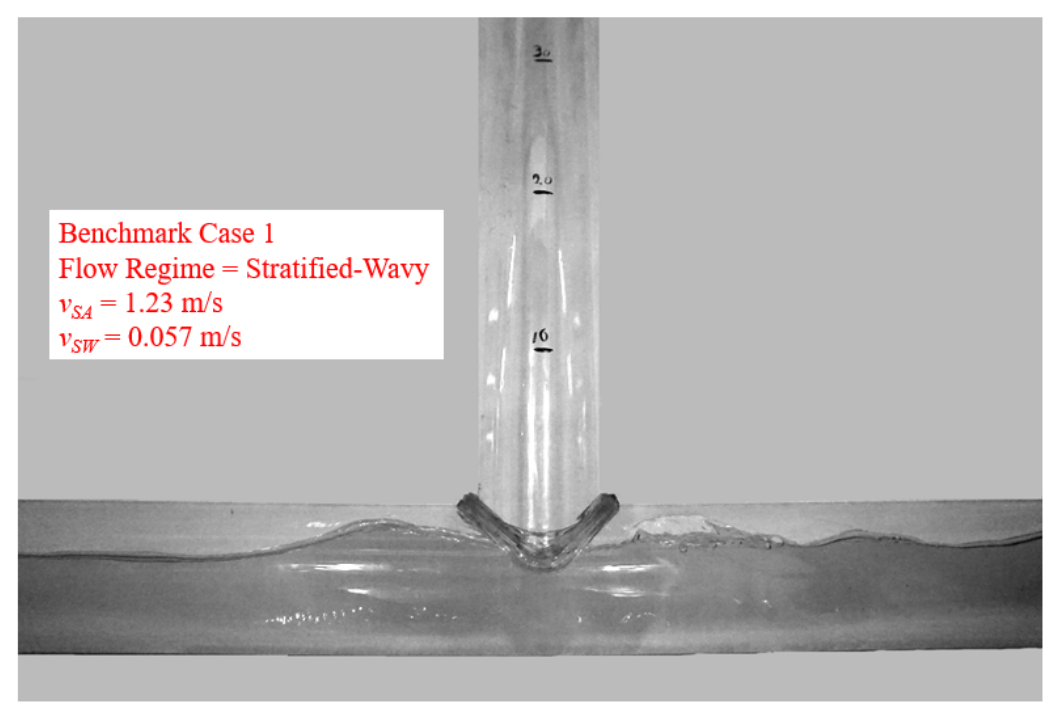

FiguRE 14. The photograph depicts the condition of the flow during benchmark case 1 .

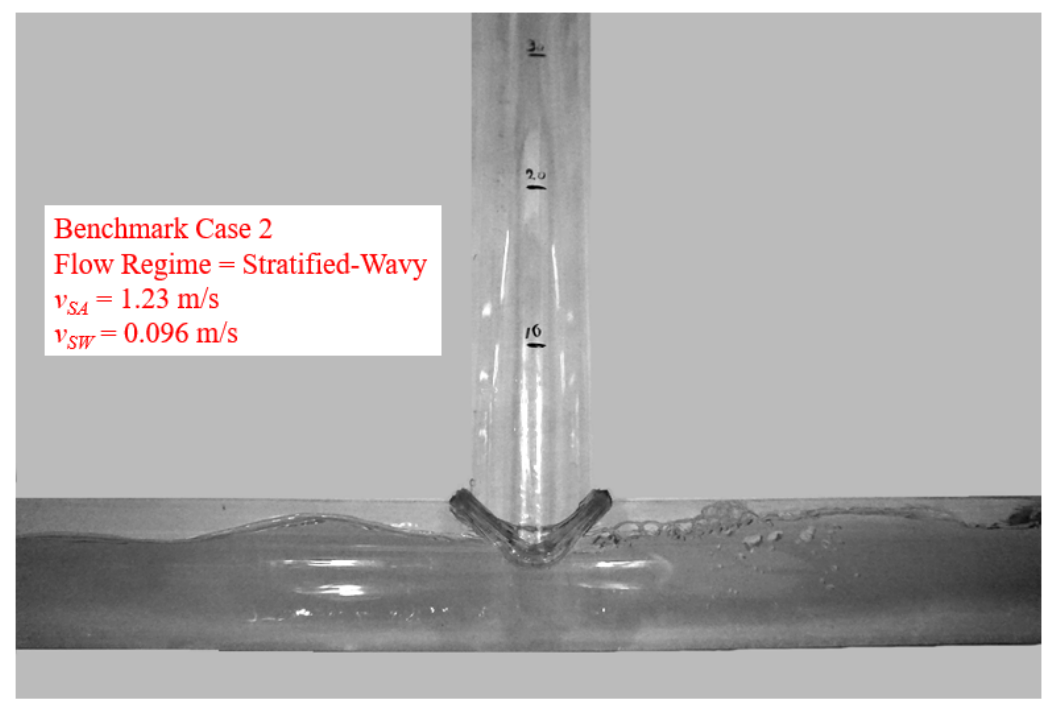

FiguRE 15. The photograph depicts the condition of the flow during benchmark case 2 .

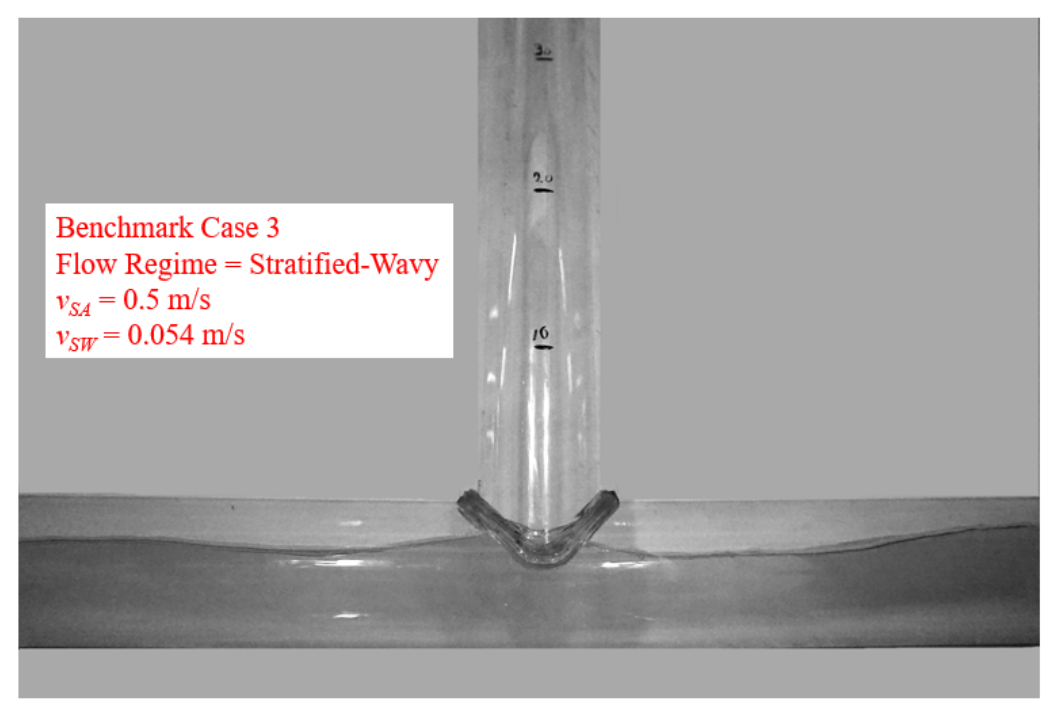

Figure 16. The photograph depicts the condition of the flow during benchmark case 3 . 


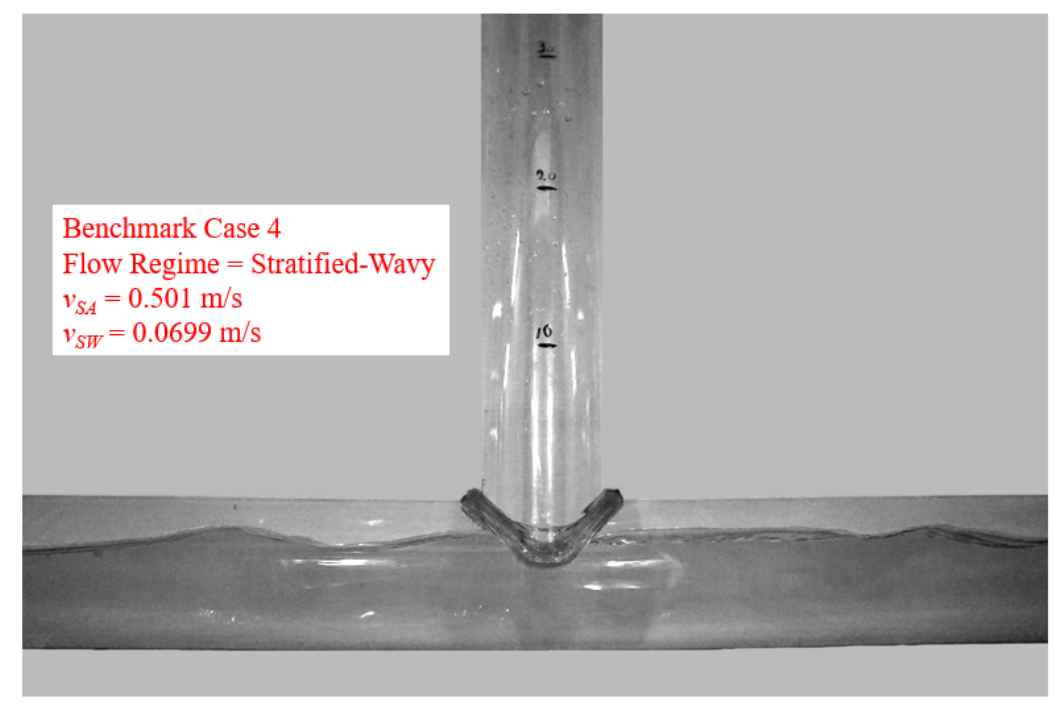

Figure 17. The photograph depicts the condition of the flow during benchmark case 4 .

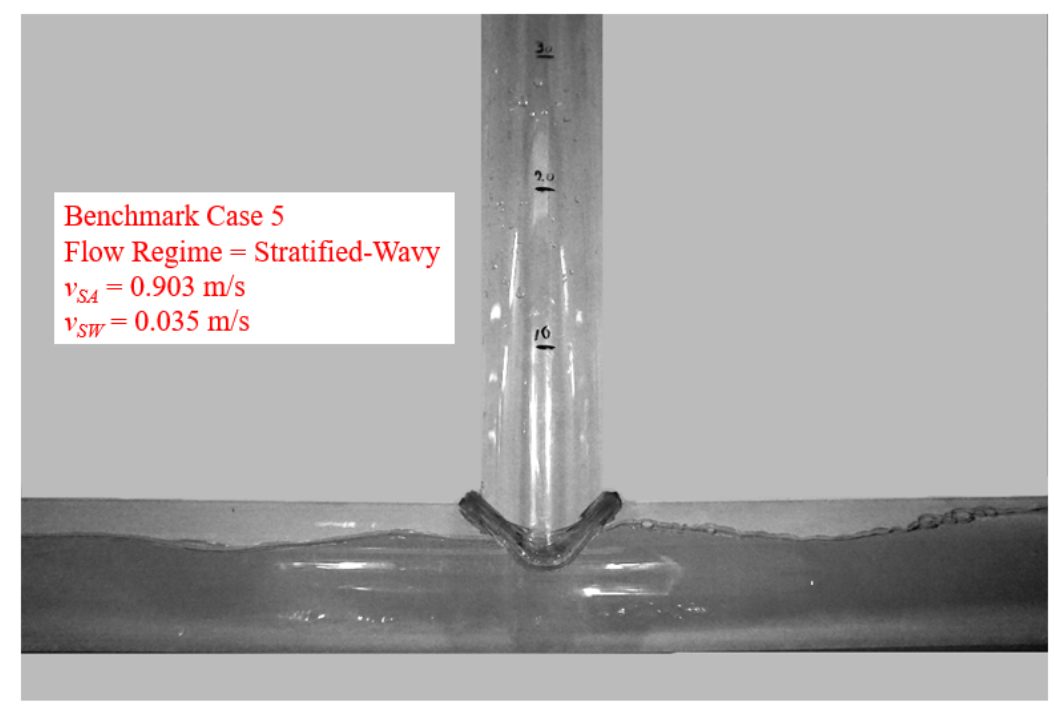

Figure 18. The photograph depicts the condition of the flow during benchmark case 5 .

\section{Conclusions}

Multiphase flow loops are one of the fundamental tools for conducting a research in the disciplines of a flow assurance. This paper presents the design and validation of a recently developed $0.078 \mathrm{~m}$ diameter, highly modular air-water flow loop. This flow loop has a test section length of $8 \mathrm{~m}$, which consists of four 2 -m pipes. Therefore, a great number of pipe profiles can be analysed on this flow loop with slight modifications. Moreover, experiments were conducted on this flow loop by replicating the operating conditions of a previously reported study, and a reasonable agreement was observed between the present results and the chosen benchmarks.

\section{ACKNowledGements}

This research is supported by the Malaysia Ministry of Higher Education under FRGS 0153ABL03 and Yayasan UTP Fundamental Research Grant under YUTP 0153AAE03.

\section{REFERENCES}

[1] Z. Memon, C. M. Tran, W. Pao, F. Hashim. Two-phase slug flow separation at T-junction with regular and reduced vertical side arm. vol. 2035, p. 050001. 2018. DOI:10.1063/1.5075572.

[2] M. Tran, Z. Memon, W. Pao, F. Hashim. Preliminary results of numerical simulation of slug flow in a regular T-junction. MATEC Web of Conferences 225:03001, 2018. DOI:10.1051/matecconf/201822503001.

[3] B. Robøle, H. Knut Kvandal, R. Schüller. The Norsk Hydro Multi Phase Flow Loop. A high pressure flow loop for real three-phase hydrocarbon systems. Flow Measurement and Instrumentation 17:163-170, 2006. DOI:10.1016/j.flowmeasinst.2006.01.003.

[4] R. Vilagines, A. R. W. Hall. Comparative behaviour of multiphase flowmeter test facilities. Oil \& G Gas Science and Technology 58:647-657, 2003. DOI:10.2516/ogst:2003045

[5] E. Mary Katie Wren. Geometric effects on phase split at a large diameter T-junction. Ph.D. thesis, University of Nottingham, 2001. 
[6] G. Das, P. K. Das, B. Azzopardi. The split of stratified gas-liquid flow at a small diameter T-junction. International Journal of Multiphase Flow 31:514-528, 2005. DOI:10.1016/j.ijmultiphaseflow.2005.01.009.

[7] G. Baker. Separation and control of gas-liquid flows at horizontal T-junctions. Ph.D. thesis, University of Nottingham, 2003.

[8] B. Azzopardi, S. Rea. Phase separation using a simple T-junction. In SPE Annual Technical Conference and Exhibition. 2000. DOI:10.2118/63040-MS.

[9] Y. Liu, W. Z. Li. Numerical simulation on two-phase bubbly flow split in a branching T-junction. International Journal of Air-Conditioning and Refrigeration 19(04):253-262, 2011. DOI:10.1142/S2010132511000612.

[10] W. Pao, A. Saieed, F. Hashim, R. B. M. Norpiah. Numerische Simulation der Zweiphasentrennung in einem T-Knoten mit kleinem Durchmesser.

Materialwissenschaft und Werkstofftechnik 48:255-260, 2017. DOI:10.1002/mawe.201600769.
[11] T. Stacey, B. Azzopardi, G. Conte. The split of annular two-phase flow at a small diameter T-junction. International Journal of Multiphase Flow 26:845-856, 2000. DOI:10.1016/S0301-9322(99)00051-8.

[12] A. Saieed, W. Pao, B. Hewakandamby, et al. Experimental investigation on the effect of diameter ratio on two-phase slug flow separation in a T-junction. Journal of Petroleum Science and Engineering 170:139-150, 2018. DOI:10.1016/j.petrol.2018.06.033

[13] A. Saieed, W. Pao, F. Hashim. Effect of T-junction diameter ratio on stratified-wavy flow separation. Journal of Natural Gas Science and Engineering 51:223-232, 2018. DOI:10.1016/j.jngse.2018.01.015

[14] A. Saieed, W. Pao, H. Ali. Prediction of phase separation in a T-junction. Experimental Thermal and Fluid Science 97:160-179, 2018. DOI:10.1016/j.expthermflusci.2018.04.019 